\title{
Changes in ventricular size and plasma renin activity after cardiac surgery in children ${ }^{\star \dagger}$
}

\author{
B D F BOURGEOIS, I OBERH ̈̈NSLI, J C ROUGE, L PAUNIER, \\ B FRIEDLI, M B VALLOTTON \\ From the Department of Pediatrics and Genetics, Anesthesiology and Internal Medicine, \\ University of Geneva, Switzerland
}

SUMMARY Plasma renin activity and one-dimensional echocardiographic measurements of the left atrium and left ventricle as well as function indices were studied repeatedly in 20 children with various cardiopathies (ages: 9 months to 15 years) before and after corrective surgery. Nine children had tetralogy of Fallot, four had pulmonary stenosis, four had rheumatic heart disease, two had ventricular septal defect, and one had atrial septal defect.

Plasma renin activity was normal preoperatively, but increased significantly immediately after surgery, was still significantly higher on the 12th postoperative day and returned to normal six to eight weeks after surgery. Patients with tetralogy of Fallot and pulmonary stenosis had higher plasma renin activity values than the others.

There was a positive correlation between plasma renin activity and postoperative percentage change of the left ventricular dimension. In patients with tetralogy of Fallot and pulmonary stenosis, this meant that plasma renin activity became normal when the preoperatively small left ventricle reached its normal dimension. This adjustment occurred slowly over a period of two months. In rheumatic heart disease and left-to-right shunt lesions, plasma renin activities became normal when the preoperatively dilated left ventricle decreased in size towards normal values; the plasma renin activities of these patients had reached normal levels by the fifth postoperative day.

The renin secretion is modulated by various factors: of these, ventricular size and pulmonary venous return seem to be of importance.

In a previous study on renal function in children on the second day after cardiac surgery, ${ }^{1}$ determinations of plasma renin activity (unpublished data) demonstrated a rise in most patients. This rise was particularly important in several cases of tetralogy of Fallot and pulmonary stenosis, and was not related to changes in renal function. An increase in plasma renin activity might be caused by different factors linked to haemodynamic changes induced by cardiac surgery. A prospective study was therefore undertaken in children who were operated on for different types of cardiac lesions, comparing plasma renin activity values and left atrial and left ventricular dimensions as well as cardiac function indices obtained before and after operation by onedimensional echocardiography.

\footnotetext{
* This work was supported in part by the Swiss National Science Foundation and the Emil Barrel Fund.

t Preliminary results of this work were presented at the Annual Meeting of the Swiss Society for Pediatric Research, Berne, 6 June 1978.

Received for publication 4 December 1979
}

\section{Subjects and methods}

A randomly selected group of 20 children was studied. Table 1 summarises their clinical data. All patients underwent open heart surgery with cardiopulmonary bypass. Their postoperative fluid management consisted of glucose 5 per cent given at a rate of $750 \mathrm{ml} / \mathrm{m}^{2}$ per $24 \mathrm{~h}$ with $2 \mathrm{mmol} / \mathrm{kg}$ per $24 \mathrm{~h}$ of $\mathrm{NaCl}$ and of $\mathrm{KCl}$, respectively. The fluid volume was progressively increased after the first postoperative day. Cardiac failure was treated in most of the patients with digoxin and diuretics (frusemide, thiazide, and spironolactone) for up to two months after operation. Whenever necessary, cardiotonic drugs were added during the first two days. Blood pressure was measured directly through an arterial catheter (mean BP) for approximately 48 hours and thereafter by auscultation. Serum electrolyte levels $\left(\mathrm{Na}, \mathrm{K}, \mathrm{Cl}, \mathrm{CO}_{2}\right)$ and serum and urine creatinine were determined daily during the first six postoperative days and weekly thereafter. 
On each patient, serial plasma renin activity determinations and echocardiograms were performed according to the following schedule:

I: preoperatively

II: 2 nd postoperative day

III: 5 th postoperative day

IV: 12 th postoperative day

V: 4 to 8 weeks postoperatively.

Blood samples were drawn, usually in the morning, after the patients had remained in the supine position for at least two hours. The samples were collected in chilled tubes containing EDTA, and were then centrifuged at $4^{\circ} \mathrm{C}$. The plasma renin activity was determined by radioimmunoassay of angiotensin I generated during one hour of incubation, ${ }^{2}$ assay being adapted to the antibody trapping method of Poulsen. ${ }^{3}$

\section{ECHOCARDIOGRAPHIC TECHNIQUE}

The echocardiogram was obtained using a Picker 80C ultrasonoscope with a $3.5 \mathrm{MHz}$ transducer $(6 \mathrm{~mm}$ diameter focused at $7 \mathrm{~cm}$ ) and a Honeywell fibreoptic strip chart recorder. The examination was performed in the supine position by the method described by Feigenbaum. ${ }^{4}$ Each echocardiogram was taken within 12 to 24 hours after blood sampling for renin. The echocardiographic indices obtained were left ventricular end-systolic and end-diastolic dimensions (Fig. 1), mean

Table Clinical data of patients

\begin{tabular}{|c|c|c|c|c|}
\hline $\begin{array}{l}\text { Case } \\
\text { no. }\end{array}$ & Age (y) & Sex & Diagnosis & Operation \\
\hline 1 & $31 / 12$ & $\mathbf{M}$ & $\mathrm{TOF}+\mathrm{ASD}$ & Total correction \\
\hline 2 & $15 / 12$ & $\mathbf{M}$ & $\mathrm{TOF}+\mathrm{ASD}$ & Total correction \\
\hline 3 & $611 / 12$ & $M$ & TOF & Total correction \\
\hline 4 & $67 / 12$ & $\mathbf{M}$ & TOF & Total correction \\
\hline 5 & $9 / 12$ & $\mathbf{M}$ & TOF & Total correction \\
\hline 6 & $11 / 12$ & $\mathbf{M}$ & TOF + ASD & Total correction \\
\hline 7 & $38 / 12$ & $M$ & $\begin{array}{l}\text { TOF + right aortic } \\
\text { arch }\end{array}$ & Total correction \\
\hline 8 & $62 / 12$ & $\mathbf{F}$ & TOF + ASD & Total correction \\
\hline 9 & $22 / 12$ & $\mathrm{M}$ & TOF & Total correction \\
\hline 10 & $58 / 12$ & $\mathbf{M}$ & $\begin{array}{l}\text { PS + bicuspid aortic } \\
\text { valve }\end{array}$ & $\begin{array}{l}\text { Pulmonary } \\
\text { commissurotomy }\end{array}$ \\
\hline 11 & $24 / 12$ & $\mathbf{M}$ & PS + VSD & $\begin{array}{l}\text { Pulmonary } \\
\text { infundibulotomy } \\
\text { patch on VSD }\end{array}$ \\
\hline 12 & $210 / 12$ & $\mathbf{M}$ & PS + ASD & $\begin{array}{l}\text { Pulmonary } \\
\text { commissurotomy }\end{array}$ \\
\hline 13 & $70 / 12$ & $\mathbf{F}$ & $\begin{array}{l}\mathrm{PS}+\mathrm{ASD}+ \\
\text { hypoplastic RV }\end{array}$ & $\begin{array}{l}\text { Pulmonary } \\
\text { infundibulotomy } \\
+ \text { patch }\end{array}$ \\
\hline 14 & $28 / 12$ & $\mathbf{M}$ & VSD + AR & Closure of VSD \\
\hline 15 & $38 / 12$ & $\mathbf{F}$ & VSD & Patch on VSD \\
\hline 16 & $99 / 12$ & $\mathbf{F}$ & ASD ( $L$ to $R$ shunt) & Closure of ASD \\
\hline 19 & $122 / 12$ & $\mathbf{M}$ & $\mathbf{M R}+\mathbf{M S}$ & Mitral Starr valve \\
\hline 20 & $150 / 12$ & $\mathbf{F}$ & MR & $\begin{array}{l}\text { Mitral Carpentier } \\
\text { ring }\end{array}$ \\
\hline 21 & $1211 / 12$ & $\mathbf{F}$ & $M R+M S$ & Mitral Starr valve \\
\hline 22 & $61 / 12$ & $\mathbf{M}$ & $\mathbf{A R}+\mathbf{A S}$ & Aortic Bjork valve \\
\hline
\end{tabular}

velocity of circumferential fibre shortening (mean Vcf), per cent shortening of the internal dimension (\% SID), and ejection fraction (EF), as previously described..$^{5-7}$ Left ventricular systolic time interval (LVSTI), that is left ventricular preejection period (LVPEP), and ejection time (LVET) were measured on the aortic root echo after determination of the aortic cusp opening and closure $^{8} 9$ (Fig. 2). The ratio of LVPEP/LVET was calculated and used as an index of left ventricular performance. ${ }^{9}$

For the statistical analyses, Student's t tests for paired and unpaired observations and linear regression with correlation were used.

The study procedure was accepted by the Ethical Committee of the Department of Pediatrics.

\section{Results}

Systemic arterial blood pressures did not change significantly before and after operation. None of these patients had perturbations of serum electrolyte levels or of the acid-base balance.

\section{PLASMA RENIN ACTIVITY (PRA)}

Mean plasma renin activity values for all patients are shown in Fig. 3. We arbitrarily separated patients with tetralogy of Fallot and pulmonary stenosis (group 1) from those with left-to-right shunts and rheumatic valvular heart disease (group 2). Though both groups showed significant differences in age, their preoperative plasma renin activity values did not differ significantly. The mean value in group 1 was $588 \mathrm{fkat}$ per litre, with a range of 42 to 2100 (mean $2 \cdot 8 \mathrm{ng} / \mathrm{ml}$ per hour; range $0 \cdot 2$ to 10 ), while the mean value in group 2 was 1029 fkat per litre, with a range of 378 to 2226 (mean $4.9 \mathrm{ng} / \mathrm{ml}$ per hour; range 1.8 to 10.6 ).

The preoperative values were within normal limits in all patients. ${ }^{1011}$ On the second postoperative day there was a sharp rise in plasma renin activities in all patients, with a progressive fall towards the 12th day and two months postoperatively, respectively. Compared with the preoperative values, the plasma renin activity was significantly higher on the second (PRA II) $(p<0.01)$, on the fifth (PRA III) $(p<0.02)$, and on the 12th (PRA IV) $(p<0.05)$ postoperative day. There was no correlation between the plasma renin activity and the age of the patients (as previously shown), the change in arterial oxygen saturation, or the change in haematocrit. The patients with high plasma renin activity values had no systemic arterial hypertension, or hypokalaemia. In patients with tetralogy of Fallot and pulmonary stenosis, the mean postoperative values were, however, higher than for the others without 


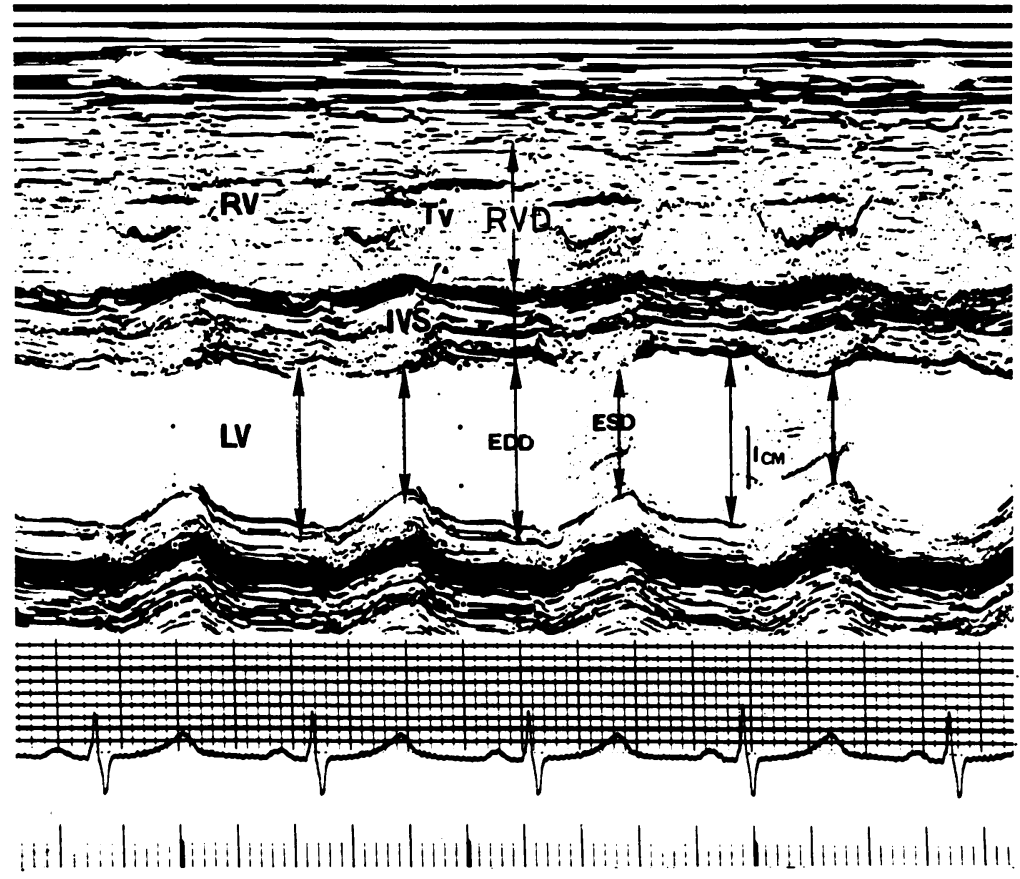

Fig. 1 Echocardiogram of the right and left ventricle in $a$ patient with tetralogy of Fallot two days after surgical correction. $R V$, right ventricle; $T V$, tricuspid valve; $L V$, left ventricle; IVS, interventricular septum; $E D D$, end-diastolic dimension; $E S D$, end-systolic dimension; $R V D$, right ventricular dimension.

tetralogy of Fallot, but this difference was significant only on the second postoperative day because of the wide dispersion of individual values.

\section{ECHOCARDIOGRAM}

In patients with rheumatic valvular heart disease and those with significant left-to-right shunts, the left atrium was very dilated before operation. This dilatation decreased after surgical correction and the left atrium approached normal size soon after the intervention. The left atrial diameter was smaller than normal in patients suffering from tetralogy of Fallot, pulmonary stenosis, or atrial septal defect before operation. After the operation,

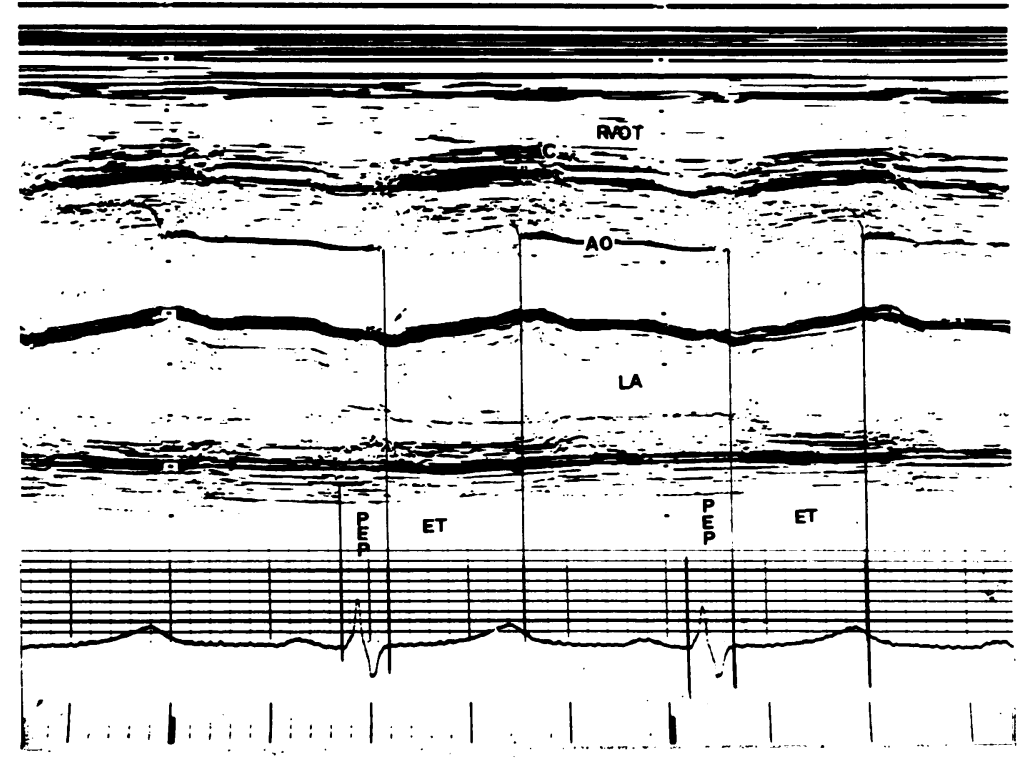

Fig. 2 Aortic valve echocardiogram of a patient with tetralogy of Fallot two days after operation. $C$, catheter in the right ventricle; RVOT, right ventricular outflow tract; Ao, aorta; $L A$, left atrium; PEP, left ventricular pre-ejection period; ET, left ventricular ejection time. 
there was a pronounced and rapid increase of left atrial dimension.

The same group of patients also had smaller left ventricular diameters before operation than normal. After corrective surgery these dimensions increased progressively, and finally reached normal diameters two months after operation (Fig. 4). The changes were highly significant as we had shown previously.? Those patients who suffered from rheumatic valvular disease or from other congenital malformations with dilated left ventricles before operation, showed a decrease in left ventricular diameters after operation (Fig. 4).

Indices of left ventricular function were calculated from left ventricular dimensions and LVSTI; the results are shown in Fig. 5a, b, c. The percentage SID of the left ventricle showed only insignificant changes throughout the postoperative period in patients with tetralogy of Fallot and pulmonary stenosis, whereas the other patients had significantly diminished values on the second postoperative day with a subsequent progressive return to normal values. The mean Vcf and the ejection fraction showed a similar pattern of changes.

Patients with tetralogy of Fallot and pulmonary stenosis maintained normal values of LVPEP/ LVET ratios, postoperatively, whereas in the other patients an increase of LVSTI ratio and abnormally high values on the second and fifth postoperative days were seen. This increase was probably a

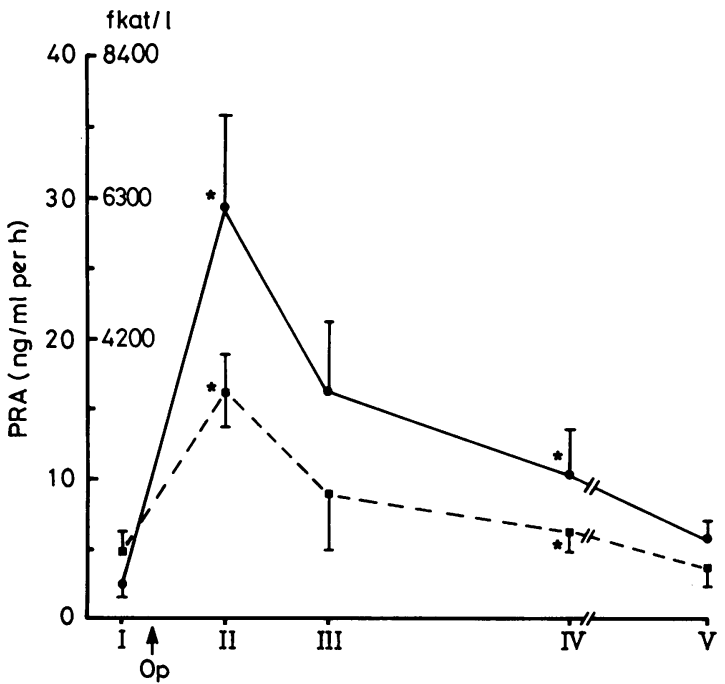

Fig. 3 Sequential plasma renin values (mean $\pm S E M$ ): (O) in patients with tetralogy of Fallot and pulmonary stenosis; $(\square)$ in patients with rheumatic heart disease and left-to-right shunts; I, preoperative values; II, III, $I V$, values on the second, fifth, and 12th postoperative days; $V$, six to eight weeks after operation; $O p$, operation; *, significant.

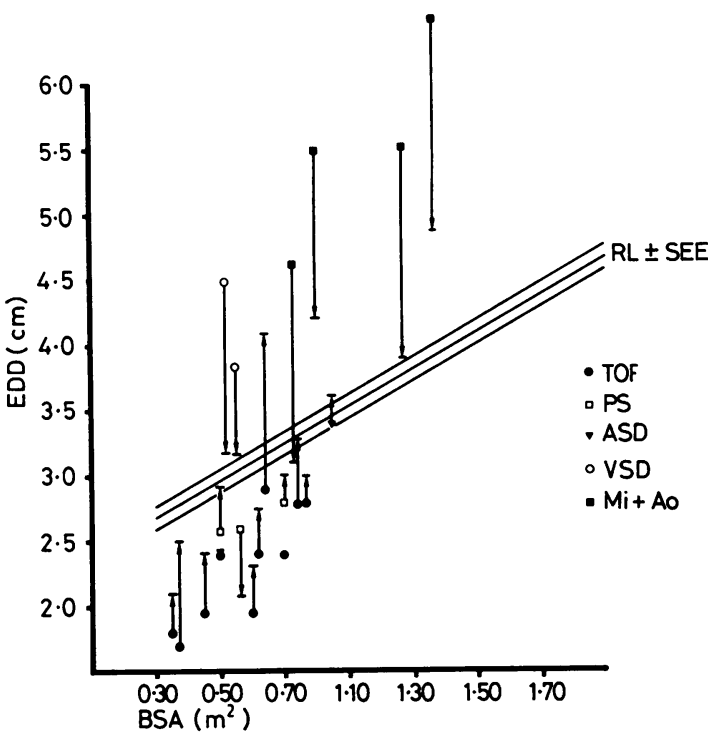

Fig. 4 Nomogram of the end-diastolic diameter (EDD) of the left ventricle according to Epstein et al. in Circulation 1975 ; 51 : 1124-9.

$(R L$, regression line $+S E E)$. The preoperative diameters of the left ventricle (LVEDD) in each patient is shown: TOF, tetralogy of Fallot; PS, pulmonary stenosis; $A S D$, atrial septal defect; $V S D$, ventricular septal defect; Mi, Ao, mitral and aortic valve disease (rheumatic heart disease). The tip of the arrow indicates the measurement on the fifth postoperative day in each patient. Tetralogy of Fallot and pulmonary stenosis show an increase in LVEDD while VSD, Mi, and Ao show a decrease in LVEDD.

result of poor left ventricular contractility. With increasing time after surgery they returned towards normal values (two months after the intervention).

RENIN VALUES VS ECHOCARDIOGRAPHIC DATA The relation between plasma renin activity values and echocardiographic indices was analysed by plotting the plasma renin activity of a given patient on a given day against his echocardiographic dimensions and function indices obtained on the same day. No correlation was found between plasma renin activity values and per cent shortening of the internal dimension values, mean Vcf, or LVPEP/ET ratio, and changes in left atrial dimensions. For each patient, the differences between the preoperative end-diastolic dimension and the end-diastolic dimension on the second, fifth, and 12th postoperative days were calculated, that is the postoperative increase or decrease in dimension. This difference was expressed as a percentage of the preoperative end-diastolic dimension value ( $\%$ change EDD) and was compared 
with the corresponding postoperative renin value. On the second postoperative day, all patients were in cardiac failure with distinctly raised plasma renin activity values and inconsistent changes in

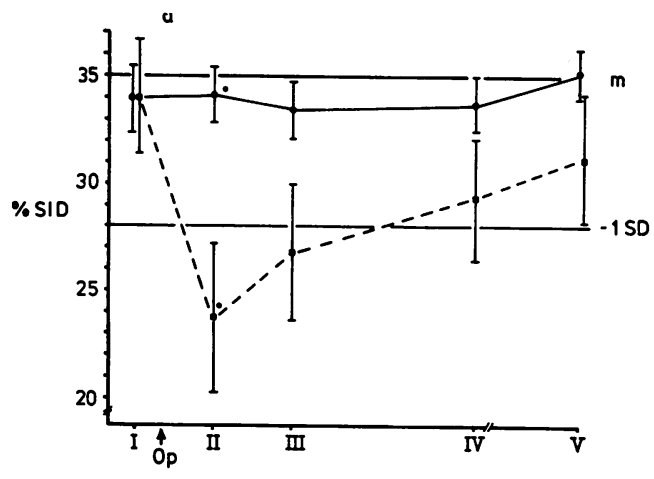

b
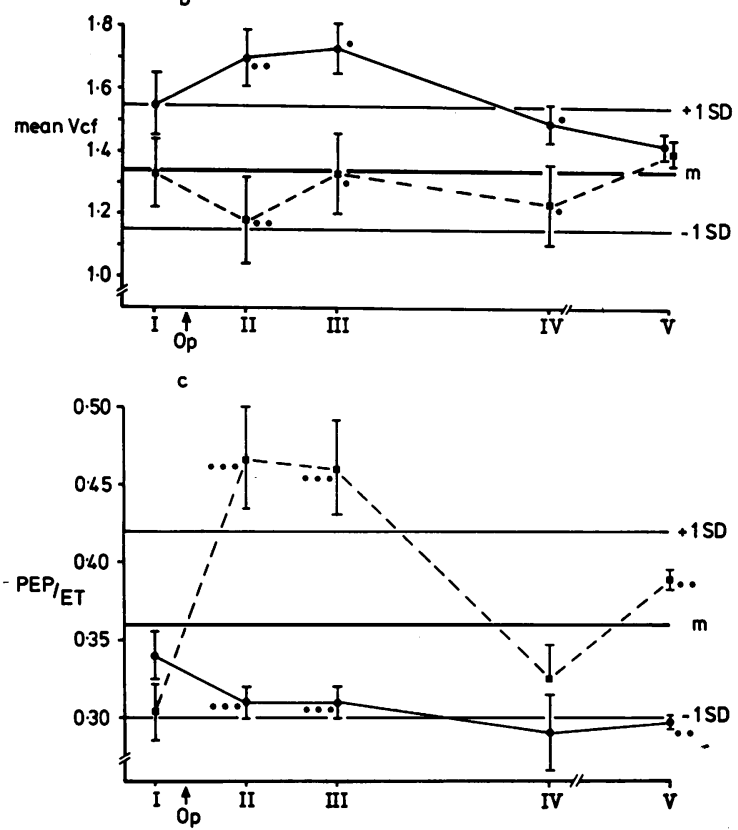

Fig. 5 Left ventricular function indices in patients with tetralogy of Fallot and pulmonary stenosis (O), and in patients with rheumatic heart disease and left-to-right shunts ( $\square$. I, preoperative values; $I I, I I I, I V$, values on the second, fifth, and 12th postoperative day; $V$, six to eight weeks postoperatively; (a) per cent shortening of the internal dimension ( $\% S I D$, mean $\pm S D$ ); (b) mean velocity of circumferential fibre shortening (mean $V c f$, mean $\pm S D)$; (c) $P E P / E T=$ left ventricular systolic time-interval ratio. The horizontal lines indicate the normal values $\pm 1 S D$. Patients with tetralogy of Fallot and pulmonary stenosis show only slightly impaired function indices; patients with rheumatic heart disease and left-to-right shunt lesions show significant changes in cardiac function. left ventricular dimensions. Therefore no correlations between plasma renin activity values and echocardiographic indices were calculated on that day. There was a significant linear correlation from the fifth postoperative day between the logarithm of the plasma renin activity values and the percentage change in end-diastolic dimension. The patients with a small ventricle that dilates postoperatively tended to have higher plasma renin activity values than the patients with a larger ventricle which decreased in size after surgery. The correlation is shown for the fifth and the 12th postoperative day in Fig. 6a and $b$.

\section{Discussion}

An increase in the activity of the renin-angiotensin system was previously reported to follow open heart surgery with cardiopulmonary bypass in adults. ${ }^{12}$ In studies with measurement of plasma renin activity, the wide dispersion of individual values is to be taken into consideration. These variations, which are important in normal children, ${ }^{13}$ are even more obvious in patients who receive cardiotonic and/or diuretic treatment for cardiac failure. ${ }^{14}$ This explains the relatively great scatter of plasma renin activity values during the postoperative period.

In the present study we observed a distinct increase in plasma renin activity on the second postoperative day in all patients. This increase could be a result of cardiopulmonary bypass, ${ }^{12}$ aortic clamping, as well as fluid restriction, ${ }^{15}$ diuretics, ${ }^{14}{ }^{16}$ and cardiotonics. ${ }^{17-19}$ Plasma renin activity values, however, remained high on the fifth and 12th postoperative day in all patients and were significantly higher in patients operated on for tetralogy of Fallot and pulmonary stenosis. The difference between the two groups cannot be explained by the type of surgery and the time on cardiopulmonary bypass. Changes in renal function (renal plasma flow and glomerular filtration rate) were not observed after cardiac surgery, 1 and, therefore, could not account for the changes in plasma renin activity. The persistence of high values on the fifth and 12th postoperative day, as well as the differences between various cardiac lesions have, to our knowledge, not yet been reported.

Postoperative haemodynamic changes observed by serial echocardiograms might help to explain the prolonged increase of renin-angiotensin activity in tetralogy of Fallot and pulmonary stenosis. Corrective surgery in these patients is followed by an increased pulmonary blood flow but also by altered geometric relation of the ventricles (the left ventricle being pushed backwards by the 
dilated right ventricle. $)^{2021}$ While the left atrium dilates rapidly, the left ventricle dilates only slowly over days and weeks. ${ }^{7}$ The most important increase in left ventricular size is, however, observed during the first three weeks after operation.

The difference in plasma renin activity between the two groups with the particularly high value of plasma renin activity in tetralogy of Fallot and pulmonary stenosis could be explained by the following hypothesis. Patients with tetralogy of Fallot and pulmonary stenosis are in acute left and right heart failure because of a non-compliant left ventricle and a malfunctioning dilated right ventricle. Acute cardiac failure is known to be accompanied by enhanced sympathetic tone, by increased activity of the adrenergic nervous system, with norepinephrine accumulations in the arterial blood, ${ }^{22}$ and by increased activity of the reninangiotensin system. ${ }^{18} 19$ Patients with rheumatic cardiopathies and shunt lesions are in chronic cardiac failure before operation and are treated with digitalis, diuretics, and a low salt diet, preoperatively. This treatment is continued after corrective surgery. Chronic heart failure is usually not accompanied by increased activity of the reninangiotensin II system. Therefore, the reninangiotensin system in patients with rheumatic cardiopathies is more stable. In addition, the left atrial and left ventricular, but also the right ventricular size of these patients diminishes after operation as seen in Fig. 4.

Left ventricular function tests obtained by echocardiography were normal or only slightly impaired in patients with tetralogy of Fallot and pulmonary stenosis while they were more disturbed in the other patients. There was, however, no correlation between the function test and the plasma renin activity, as previously shown by Turini et al. $^{23}$

The mechanism controlling the renin release in congestive heart failure has not yet been well defined. ${ }^{19}$ Numerous studies suggest that-besides adrenergic system regulating mechanisms-pressure receptors in the heart and great arteries may modify the release of renin. Cardiopulmonary mechanoreceptors might play the most important role. ${ }^{24-26}$ The role of these receptors, however, remains questionable, and the published reports are contradictory. ${ }^{24} 2527-32$

Plasma renin activity values decrease when the left ventricle dilates and approaches its normal size in patients with tetralogy of Fallot and pulmonary stenosis (Fig. 6a, b). Increased plasma renin activity values persist, however, certainly until the 12th postoperative day, but are less pronounced
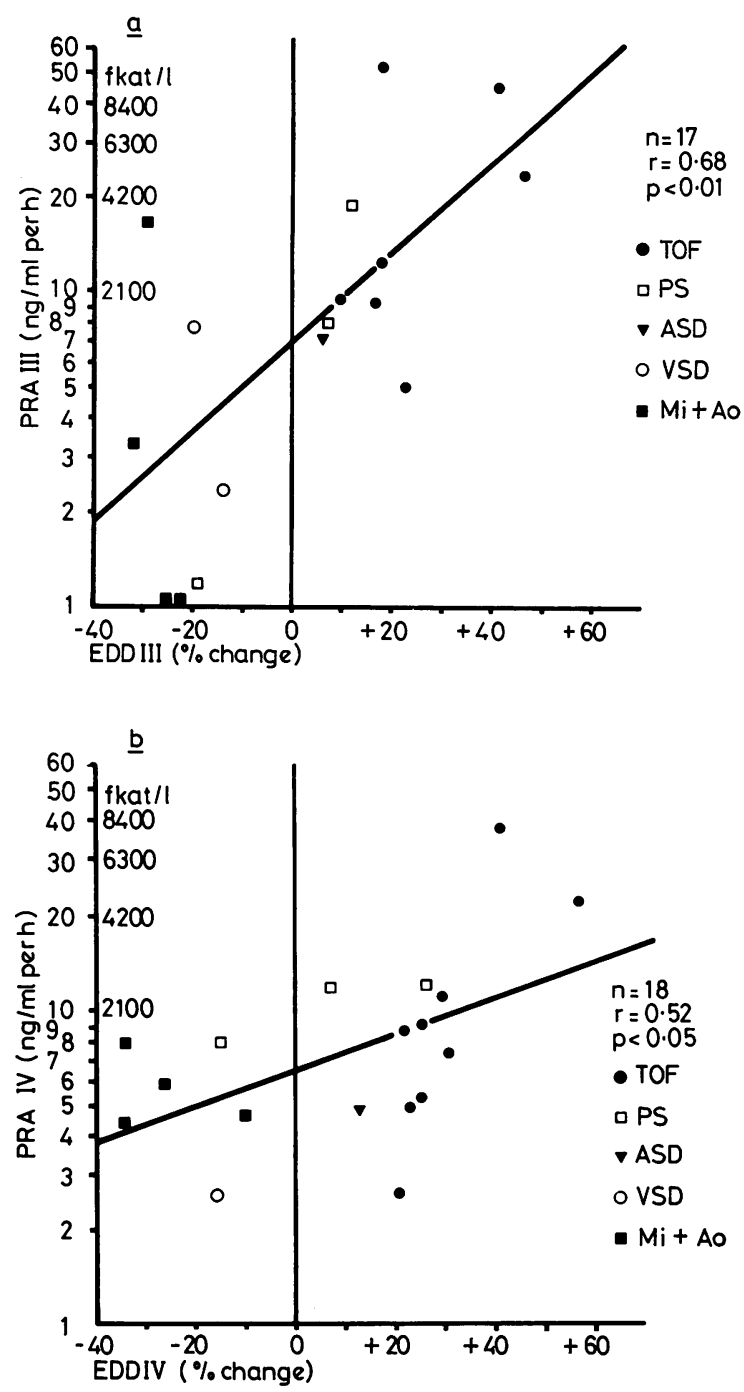

Fig. 6 Graphic representation of the correlation between plasma renin activity (PRA) and the percentage change between pre- and postoperative LVEDD (\% change $E D D)$. Regression lines are indicated. (a) On the fifth postoperative day (III); (b) on the 12th postoperative day (IV).

at that time since the left ventricle has returned to normal size. In patients with a preoperatively dilated left atrium and dilated left ventricle, plasma renin activity decreases when left atrial and left ventricular size diminishes. These changes in size occur more rapidly and more significantly in the first postoperative days. In both groups of patients the interaction between changes in ventricular size and venous return seems to modulate the renin secretion via different cardiopulmonary receptors. 


\section{References}

1 Bourgeois BFD, Donath A, Paunier L, Rouge JC. Effects of cardiac surgery on renal function in children. $\mathcal{F}$ Thorac Cardiovasc Surg 1979; 77: 283-6.

2 Vallotton MB. Parallel radioimmunoassays of angiotensin I and of angiotensin II for measurement of renin activity and of circulating active hormone in human I lasma (abstract). Horm Metab Res 1970; Suppl 3: 94 .

3 Poulsen K. Simplified method for radioimmunoassay of enzyme system: application on the human reninangiotensin system. f Lab Clin Med 1971; 78: 309-15.

4 Feigenbaum HL. Echocardiography. Philadelphia: Lea \& Febiger, 1976.

5 Cooper RH, O'Rourke RA, Karliner JS, Peterson KL, Leopold GR. Comparison of ultrasound and cineangiographic measurements of mean rate of circumferential fiber shortening in man. Circulation 1972; 46: 914-23.

6 Meyer RA, Stockert J, Kaplan S. Echographic determination of left ventricular volumes in pediatric patients. Circulation 1975; 51: 297-303.

7 Oberhänsli I, Friedli B. Echocardiographic study of left and right ventricular dimension and left ventricular function in patients with tetralogy of Fallot, before and after surgery. Br Heart $\mathcal{F} 1979$; 41 : 40-53.

8 Hirschfeld ST, Meyer RA, Schwartz DC, Korfhagen J, Kaplan S. Measurement of right and left ventricular systolic time intervals by echocardiography. Circulation 1975; 51: 304-9.

9 Weissler AM, Lewis RP, Leighton RF. The systolic time interval as a measure of left ventricular performance in man. In: Yu PN, Goodwin JF, eds. Progress in cardiology. Vol. 1. Philadelphia: Lea \& Febiger, 1972: 155-83.

10 Hiner LB, Gruskin AB, Baluarte HJ, Cote ML. Plasma renin activity in normal children. $\mathcal{f}$ Pediatr 1976; 89: 258-61.

11 Stalker HP, Holland NH, Kotchen JM, Kotchen TA. Plasma renin activity in healthy children. $\mathcal{F}$ Pediatr 1976; 89: 256-8.

12 Taylor KM, Morton IJ, Brown JJ, Bain WM, Caves PK. Hypertension and the renin-angiotensin system following open heart surgery. $\mathcal{f}$ Thorac Cardiovasc Surg 1977; 74: 840-5.

13 Dillon MJ, Ryness JM. Plasma renin activity and aldosterone concentration in children. $\mathrm{Br} \mathrm{Med} \mathcal{f}$ 1975; iv: 316-9.

14 Kaplan NM, Kem DC, Holland OB, Kramer NJ, Higgins J, Gomez-Sanchez C. The intravenous furosemide test: a simple way to evaluate renin responsiveness. Ann Intern Med 1976; 84: 639-45.

15 Kimura, T, Minai, K, Matsui $\mathrm{K}$, et al. Effect of various states of hydration on plasma $\mathrm{ADH}$ and renin in man. $\mathcal{f}$ Clin Endocrinol Metab 1976; 42: 79-87.

16 Zanchetti AS. Neural regulation of renin release. Experimental evidence and clinical implications in arterial hypertension. Circulation 1977; 56: 691-8.

17 Antonello A, Carguielli G, Ferrari M, Melacini P, Montanaro D. Effect of digoxin on plasma-renin activity in man (letter) Lancet 1976; ii: 850.

18 Franciosa JA, Cohn JN. Hemodynamic responsiveness to short and long term vasodilatators in left ventricular failure. $\mathrm{Am} \mathcal{F} \mathrm{Med} 1978$; 65: 126-33.

19 Watkins L, Burton JA, Haber E, Cant JR, Smith $\mathrm{FW}$, Barger $\mathrm{C}$. The renin-angiotensin aldosterone system in congestive failure in conscious dogs. $7 \mathrm{Clin}$ Invest 1976; 57: 1606-17.

20 Laver MB. Right ventricular function: a limiting factor. In: Zentraleuropäischer Anesthesie-Kongress 1977. Médecine et Hygiène, Genève. 1979: 263-7.

21 Pontoppidan H, Wilson RS, Rie MA, Schneider RC. Respiratory intensive care. I. Evolution of respiratory care. Anesthesiology 1977; 47: 96-116.

22 Braunwald E. Alterations in the function of the adrenergic nervous system in heart failure. Bull Eur Physiopathol Respir 1979; 15: 881-96.

23 Turini GA, Brunner HR, Ferguson RK, Rivier JL, Gavras $H$. Congestive heart failure in normotensive man. Haemodynamics, renin and angiotensine II blockade. $\mathrm{Br}$ Heart $\mathcal{F}$ 1978; 40: 1134-42.

24 Brennan LA Jr, Malvin RL, Jochim KE, Roberts DE. Influence of left and right atrial receptors on plasma concentrations of $\mathrm{ADH}$ and renin. $\mathrm{Am} \mathcal{F}$ Physiol 1971; 221 : 273-8.

25 Mancia G, Romero JC, Shepherd JT. Continuous inhibition of renin release in dogs by vagally innervated receptors in the cardiopulmonary region. Circ Res 1975; 36: 529-35.

26 Kiowski W, Julius S. Renin response to stimulation of cardiopulmonary mechanoreceptors in man. $\mathcal{f}$ Clin Invest 1978; 62: 656-63.

27 Johnson JA, Davis JO, Gotschall RW, et al. Evidence for an intravenal beta receptor in control of renin release. Am F Physiol 1976; 230: 410-8.

28 Thames MD. Reflex suppression of renin release by ventricular receptors with vagal afferents. $A m \mathcal{F}$ Physiol 1977; 233: H 181-4.

29 Thames MD, Jarechi M, Donald DE. Neural control of renin secretion in anesthetized dogs. Interaction of cardiopulmonary and carotid baroreceptors. Circ Res 1978; 42: 237-45.

30 Thorén PH. Activation of left ventricular receptors with nonmedullated vagal afferent fibers during occlusion of a coronary artery in the cat. $A m \mathfrak{f}$ Cardiol 1976; 37: 1046-51.

31 Yun JCH, Delea CS, Bartter FC, Kelly G. Increase in renin release after sinoaortic denervation and cervical vagotomy. Am $\mathcal{F}$ Physiol 1976; 230: 777-83.

32 Zehr JE, Hasbargen JA, Kurz KD. Reflex suppression of renin secretion during distention of cardiopulmonary receptors in dogs. Circ Res 1976; 38: 232-9.

Requests for reprints to Professor Luc Paunier, Clinique Universitaire de Pédiatrie, 30 Boulevard de la Cluse, CH-1211 Geneva 4, Switzerland. 